\title{
Correlation of generalized joint hypermobility and selective joint hypermobility with physical activity in school going children of age 6 to 12 years
}

\author{
Abhijeet A. Deshmukh ${ }^{1}$, Ruchi K. Humane ${ }^{2, *}$ \\ ${ }^{\mathbf{1}}$ Assistant Professor, ${ }^{2}$ Internee Student, Dept. of Neuro-Physiotherapy, VSPM College of Physiotherapy, Nagpur, Maharashtra, \\ India
}

*Corresponding Author:

Email: ruchieehumane@gmail.com

\begin{abstract}
Joint hypermobility is a common condition among infants and young children. Several complications like joint pain, instability, dislocation, frequent ligament injuries are commonly associated in children with joint hypermobility. Due to these complications, children may show poor control of pain, disruption of normal life, schooling as well as physical activities. Till date, very few studies evaluated school age children for joint hypermobility but no study present in central India, hence this study is proposed. Children of age 6 to 12 years $(n=3019$, males $=1650$, females $=1369)$ were disintegrated into two groups: Generalized Joint Hypermobility $(n=523$, males $=15.27 \%$, females $=19.79 \%)$ and selective joint hypermobility $(n=975$, males $=31.75 \%$, females $=32.94 \%$ ) according to Beighton's criteria. Karl Pearson's product moment was used to evaluate correlation between hypermobility, physical activity and PAQ-C was established. Step wise regression was used to calculate correlation of anthropometric data and joint hypermobility with PAQ-C. The $r$ value -0.16 and $p$ value $=0.0001$ showed that there was high significant, negative poor correlation between joint hypermobility and physical activity in age group of 6-12 years. This study concluded that children with selective joint hypermobility showed higher physical activity level as compared to children with generalized joint hypermobility as well as children with joint hypermobility showed moderate correlation with physical activity.
\end{abstract}

Keywords: Joint hypermobility, Generalized joint hypermobility, Selective joint hypermobility, Physical activity, Children 6-12 years, Correlation.

\section{Introduction}

Joint hypermobility is a condition in which an individual synovial joint have more than normal range of motion, it is either generalized or selective (single joint involvement). ${ }^{1}$ Joint hypermobility syndrome (JHS) also shows overlapping features with genetic disorders such as Marfan's and Ehler-Danlos syndrome. ${ }^{2}$ The JHS is much more common in infants and young children as compared to adults and it affects approximately $13-50 \%$ of children worldwide. ${ }^{3-6}$ It is commonly associated with symptoms like chronic joint pain, ${ }^{1,7}$ instability, poor joint perception, ${ }^{7}$ arthralgia, joint swelling often after physical activity, severe cartilage damage in the knee and multi-system involvement which may lead to frequent injuries like sprains and dislocations. ${ }^{7}$ The delay in diagnosis and treatment $^{2}$ results in poor control of pain and disturbance in daily activity, schooling, sports and physical activities. ${ }^{2,8-13}$ Joint hypermobility is multifactorial which varies with age, gender, ethnicity and family history. ${ }^{2}$ Girls are generally more hypermobile than boys and the prevalence of joint hypermobility decreases with increasing age. ${ }^{14-19}$ Hypermobility have a significant impact on quality of life of children. ${ }^{7,14-19}$ Hypermobile children spend more time in sitting and are consequently more sedentary which might cause alteration in mobility and physical activity. ${ }^{14}$ Hypermobile children usually complains clicking or cracking of joints, handwriting difficulties, clumsiness and poor coordination, easy bruising, delayed first walking, reduced muscle strength, stamina and report excess fatigue. ${ }^{2}$
The prevalence of asymptomatic generalized joint hypermobility $(\mathrm{GJH})$ in children has been variably and widely reported between $2.3 \%$ to $30 \% .^{1-2,15-19}$ The study performed in India showed a prevalence of GJH i.e. $58.7 \%$ respectively in Mumbai (2008) and Lucknow (2014) whereas in Chennai (1996) showed a prevalence of $17.2 \%$ on 1000 children by using Carter and Wilkinson scoring system for joint hypermobility. ${ }^{4-5,20}$ GJH is said to be more prevalent among girls than boys with gender ratios of approximately $3: 1$ to $2: 1$, females/males. ${ }^{15-18,21-25}$ Many studies have been performed on the prevalence of joint hypermobility among children using Beighton's criteria as a reference. ${ }^{2,4-7,21-22}$ On the basis of the detailed analysis of range of motion (ROM) of all the major joints, the Beighton (BT) score was found to be a valid measure for GJH in school-age children of 6-12 years. ${ }^{1,4,14}$ The Beighton scale is considered to be the gold standard test for diagnosis of joint hypermobility and found an acceptable concurrent validity against goniometer in 6 to 12 years children. ${ }^{4}$ It is easy and quick to perform ${ }^{1}$. In present study, BT score $\geq 4 / 9$ is considered as generalized joint hypermobility while score $<4 / 9$ is considered as selective joint hypermobility. ${ }^{1}$ Many children were classified as hypermobile by use of a threshold of 5/9 was confirmed with prevalence of $35.6 \%$ (U.K. population) which was greater than an earlier study in which GJH were $11.1 \%$ of the Dutch population (4-12 years of age).$^{1}$ In 2005 , a study was conducted by N. Adib and associates on GJH and SJH on 125 children out of which 94 children showed GJH $(75.2 \%)$ with SJH i.e. knee $92 \%$, elbow $87 \%$, wrist $82 \%$ 
and MCP $79 \%$ respectively and ankle $75 \% .^{2}$ In most of studies, physical activity of children was measured by using accelerometer or self-administered questionnaire. ${ }^{7,21-22}$ Accelerometer is costlier whereas self-administered questionnaire are easy to understand and quick to perform. ${ }^{7-9,21-22}$ There are few studies available that are done on physical activity of children by using different modes such as (APARQ) Adolescent physical activity recall questionnaire, ${ }^{7}$ (CHAQ) Childhood health Assessment Questionnaire ${ }^{21-22}$ and (PAQ-C) Physical activity questionnaire for children. ${ }^{8-9}$ Out of which PAQ-C was most common and valid tool to measure physical activity level in school age children $^{8-13}$ hence, used as an outcome measure in present study. Very few studies suggest that children with joint hypermobility shows reduced physical activity. 2,22 Till date no study has been done on comparison of GJH and SJH with physical activity. In central India no study has been performed on the prevalence of joint hypermobility as well as comparison of joint hypermobility with the level of physical activity among children of age 6-12 years.

\section{Materials and Methods}

The study was performed on asymptomatic healthy children of age group 6-12 years were selected from different schools, Nagpur.

Study Design: An observational comparative study.

Sampling Method: Convenient sampling.

Sample Size: 3019 (Boys=1650, Girls=1369).

Duration of Study: 5 months.

Study Setting: Schools of Nagpur. (1=rural, 9=urban).

Materials Used: Weighing machine, Universal halfcircle goniometer, Finger goniometer, Measuring tape, Ruler scale, Physical Activity Questionnaire for Children (PAQ-C) (Fig. 1-5).

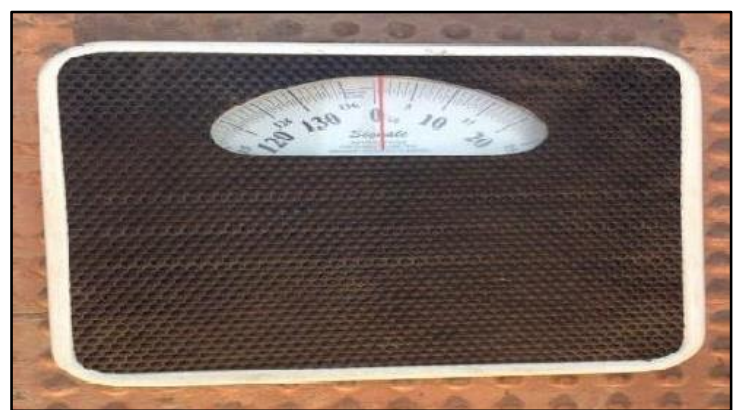

Fig. 1: Weighing machine

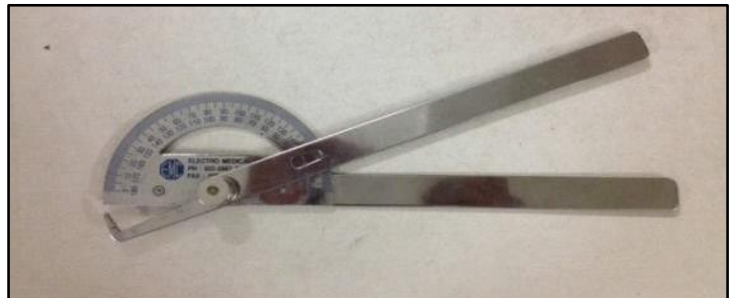

Fig. 2: Universal half circle goniometer

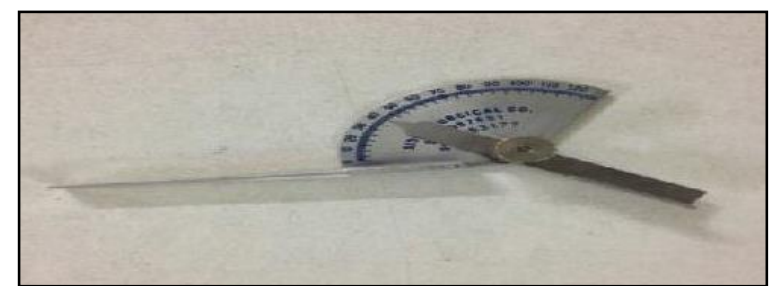

Fig. 3: Finger goniometer

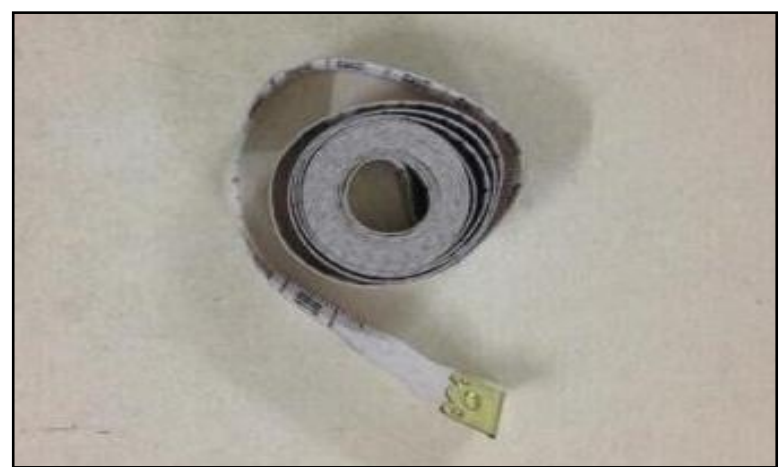

Fig. 4: Measuring tape

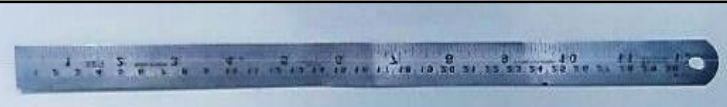

Fig. 5: Ruler scale

The approval was obtained from the Institutional Ethics Committee to carry out the research work. Study was performed over 5 months period in 10 schools of Nagpur, India. 10 schools were selected randomly by random number table method. After explaining the need for study to school authority, permission was taken. 3019 students were targeted for the study (6-12 years age). Consent was taken from each subject and teachers were taken. Procedure was explained in detail to the subject and teachers. Name, age, gender and demographic data-height (Fig. 6), weight (Fig. 7), BMI were taken. Children were assessed for joint hypermobility (Fig. 8-11) on the basis of Beighton's criteria. Children with Beighton's score $\geq 4 / 9$ were considered as GJH whereas children with Beighton's score $<4 / 9$ were considered as $\mathrm{SJH}$ as well as individual joint involvement was noted in order to find out the prevalence of SJH. After Beighton's score was taken, PAQ-C was filled up from each hypermobile child by the researcher. Data was collected and then analyzed. 


\section{Demographic Data}

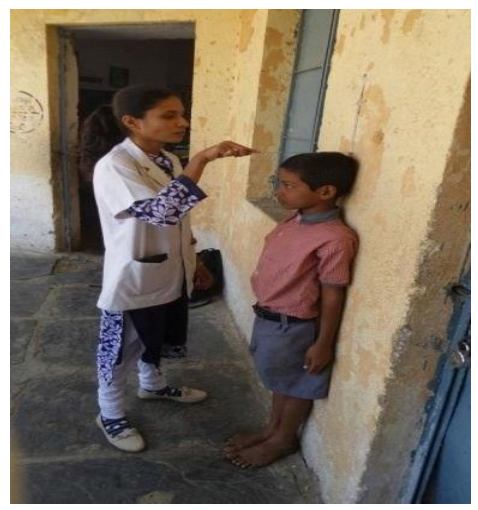

Fig. 6: Height measurement

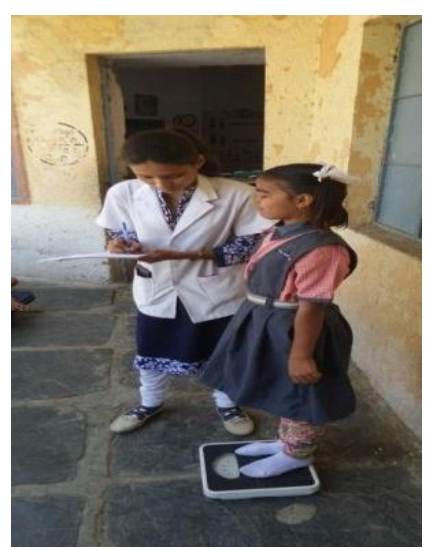

Fig. 7: Weight measurement

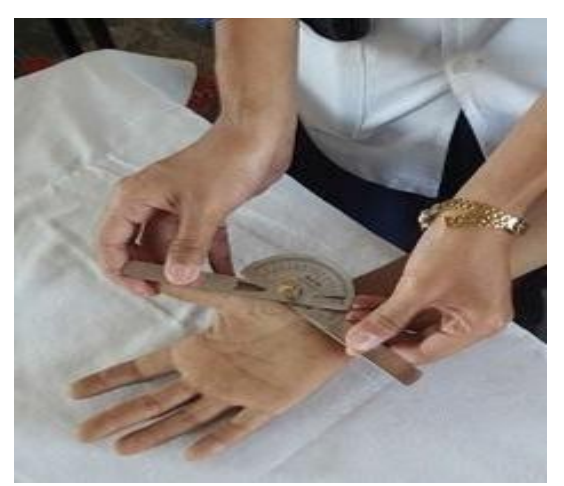

Fig. 8: Hyperextension of Thumb

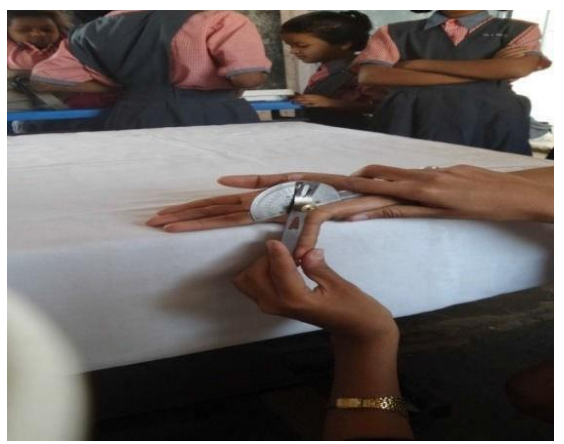

Fig. 9: Hyperextension of $5^{\text {th }} \mathrm{MCP}$

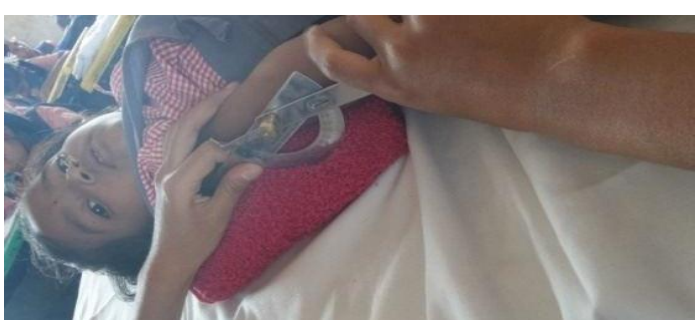

Fig. 10: Hyperextension of Elbow

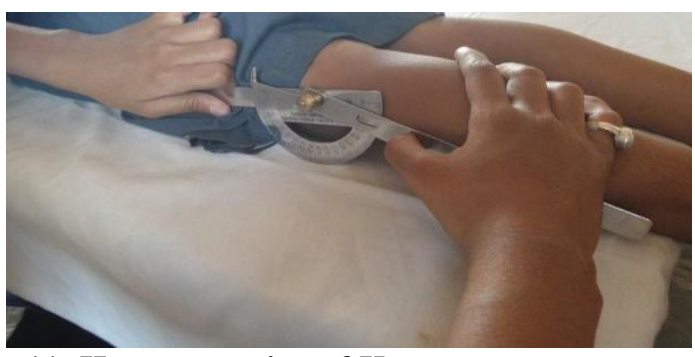

Fig. 11: Hyperextension of Knee

\section{Data Analysis}

Statistical software STATA (version 10.1, year 2011) was used to analyze the data. In present study two groups were made: 1 . GJH and 2. SJH and these two groups were compared with age, gender, height, weight, BMI percentile and physical activity. Chi Square test was used for comparing difference in proportions in two groups (GJH and $\mathrm{SJH})$.Unpaired ttest was used for comparing means of two groups $(\mathrm{GJH}$ and $\mathrm{SJH})$. Pearson's correlation coefficient (r) was used to assess degree and nature of relationship between two continuous variables (1. GJH and 2. SJH with age, height, weight, BMI percentile and physical activity). Significance of $\mathrm{r}$ value was tested with $\mathrm{t}$-test. $\mathrm{P}$ value $<0.05$ was considered as statistical significance.

\section{Results}

Prevalence of Joint Hypermobility: Out of 3019 children (6-12 years), $49.69 \%$ were hypermobile (i.e. Both $\mathrm{GJH}=17.49 \% \mathrm{SJH}=32.20 \%$ ) and $50.31 \%$ were normal (Table 1.1). Thumb-35.04\%, $5^{\text {th }}$ MCP. $24.67 \%$, Knee $-20.19 \%$, Elbow-19.94\%.

Table 1.1: Prevalence of joint hypermobility in children with age 6-12 years

\begin{tabular}{|l|c|c|}
\hline \multicolumn{1}{|c|}{ Categories } & Numbers & Percentages \\
\hline GJH & 528 & $17.49 \%$ \\
\hline SJH & 972 & $32.20 \%$ \\
\hline Normal & 1519 & $50.31 \%$ \\
\hline Total & 3019 & $100 \%$ \\
\hline Total & 1500 & $49.69 \%$ \\
\hline (GJH+SJH) & & \\
\hline
\end{tabular}

Lumbar-0.16\% i.e. (Thumb $>5^{\text {th }}$

$\mathrm{MCP}>$

Knee > Elbow > Lumbar) (Table 1.2). Limb wise Hypermobility follows the sequence: Upper limb hypermobility (79.65\%) was More common than Lower 
limb hypermobility $(20.19 \%)$ while Lumbar was the least hypermobile joint $(0.16 \%)$ (Table 1.3$)$.

Table 1.2: Individual joint hypermobility

\begin{tabular}{|l|c|c|}
\hline \multicolumn{1}{|c|}{ Joints } & JHM (N) & Percentage\% \\
\hline $5^{\text {th }}$ MCP & 1091 & $24.67 \%$ \\
\hline Thumb & $\mathbf{1 5 5 0}$ & $\mathbf{3 5 . 0 4 \%}$ \\
\hline Elbow & 882 & $19.94 \%$ \\
\hline Knee & 893 & $20.19 \%$ \\
\hline Trunk & 7 & $0.16 \%$ \\
\hline Total & 4423 & $100 \%$ \\
\hline
\end{tabular}

Table 1.3: Total hypermobility (JHM) in \%

\begin{tabular}{|l|c|c|}
\hline \multicolumn{1}{|c|}{ Hypermobility } & Numbers (n) & \% \\
\hline $\begin{array}{l}\text { Upper limb } \\
\text { hypermobility }\end{array}$ & 3523 & 79.65 \\
\hline $\begin{array}{l}\text { Lower limb } \\
\text { hypermobility }\end{array}$ & 893 & 20.19 \\
\hline $\begin{array}{l}\text { Trunk } \\
\text { hypermobility }\end{array}$ & 7 & 0.16 \\
\hline
\end{tabular}

Gender wise distribution of Joint Hypermobility: The demographic data of our study showed that both genders lies within the normal height, weight and BMI percentile. $^{26} \mathrm{GJH}$ was common among girls as compared to boys (2.66\%) (Table 2.1). SJH was common among boys as compared to girls (7.40\%) (Table 2.2). In boys, lower limb hypermobility $(54.31 \%)$ was more common as compared to upper limb hypermobility (49.47\%) i.e. (LL HM UL HM). In girls, upper limb hypermobility $(50.52 \%)$ was more common as compared to lower limb hypermobility $(45.69 \%)$ i.e. (UL HM > LL HM) (Table 2.3 and 2.4). The present study showed that incidence of hypermobility in both boys and girls increases as age advances from 6 to 10 years but showed decrement in the age of 11 and 12 year (Table 2.5, 2.6 and 2.7).

Table 2.1: Prevalence of GJH in boys and girls

\begin{tabular}{|l|c|c|}
\hline Gender & GJH(n) & \% \\
\hline Boys & 257 & 48.67 \\
\hline Girls & 271 & 51.33 \\
\hline Total & 528 & 100 \\
\hline
\end{tabular}

Table 2.2: Prevalence of SJH in boys and girls

\begin{tabular}{|l|c|c|}
\hline Gender & SJH(n) & \% \\
\hline Boys & $\mathbf{5 2 2}$ & $\mathbf{5 3 . 7 0}$ \\
\hline Girls & 450 & 46.30 \\
\hline Total & 972 & 100 \\
\hline
\end{tabular}

Table 2.3: Hypermobility \% in boys $(n=779)$

\begin{tabular}{|l|c|c|}
\hline \multicolumn{1}{|c|}{ Hypermobility } & Numbers(n) & Percentages \% \\
\hline Upper limb hypermobility & 1743 & 49.47 \\
\hline Lower limb hypermobility & 485 & 54.31 \\
\hline Trunk hypermobility & 5 & 71.42 \\
\hline
\end{tabular}

Table 2.4: Hypermobility \% in Girls $(n=721)$

\begin{tabular}{|l|c|c|}
\hline \multicolumn{1}{|c|}{ Hypermobility } & Numbers (N) & Percentages \% \\
\hline Upper limb hypermobility & 1780 & 50.52 \\
\hline Lower limb hypermobility & 408 & 45.69 \\
\hline Trunk hypermobility & 2 & 28.57 \\
\hline
\end{tabular}

Table 2.5: Age-wise distribution of subjects (boys and girls) in percentage

\begin{tabular}{|l|c|c|}
\hline \multicolumn{1}{|c|}{ Age in years } & Number of subjects & Percentages \\
\hline 6 & $\mathrm{n}=377$ & $12.49 \%$ \\
\hline 7 & $\mathrm{n}=415$ & $13.75 \%$ \\
\hline 8 & $\mathrm{n}=407$ & $13.48 \%$ \\
\hline 9 & $\mathrm{n}=452$ & $14.97 \%$ \\
\hline 10 & $\mathrm{n}=562$ & $18.62 \%$ \\
\hline 11 & $\mathrm{n}=487$ & $16.13 \%$ \\
\hline 12 & $\mathrm{n}=319$ & $10.57 \%$ \\
\hline Total & 3019 & $100 \%$ \\
\hline
\end{tabular}

Table 2.6: Age wise distribution of hypermobility in boys

\begin{tabular}{|l|c|c|c|}
\hline \multicolumn{1}{|c|}{ Age } & Total Boys & Hypermobile & (Out of 3019)\% \\
\hline 6 & 207 & 110 & 3.64 \\
\hline 7 & 228 & 109 & 3.61 \\
\hline 8 & 206 & 104 & 3.44 \\
\hline 9 & 246 & 124 & 4.10 \\
\hline 10 & 293 & 145 & 4.80 \\
\hline
\end{tabular}




\begin{tabular}{|l|c|c|c|}
\hline 11 & 276 & 116 & 3.84 \\
\hline 12 & 194 & 71 & 2.35 \\
\hline Total & 1650 & 779 & 25.80 \\
\hline
\end{tabular}

Table 2.7: Age wise distribution of hypermobility in Girls

\begin{tabular}{|l|c|c|c|}
\hline \multicolumn{1}{|c|}{ Age } & Total Girls & Hypermobile & (out of 3019)\% \\
\hline 6 & 170 & 90 & 2.98 \\
\hline 7 & 187 & 110 & 3.64 \\
\hline 8 & 201 & 107 & 3.54 \\
\hline 9 & 206 & 112 & 3.71 \\
\hline 10 & 269 & 142 & 4.70 \\
\hline 11 & 211 & 104 & 3.44 \\
\hline 12 & 125 & 56 & 1.85 \\
\hline Total & 1369 & 721 & 23.88 \\
\hline
\end{tabular}

Correlation of Anthropometric Measurements with Joint Hypermobility

1. Correlation of JHM with BMI percentile $t$ value $=$ $0.5231, \mathrm{P}=0.6010$ (NS).
2. Correlation of JHM with Age: $\mathrm{t}$ value $=1.0068$, $\mathrm{P}=0.3142$ (NS) No correlation was found between anthropometric measurements and joint hypermobility (Table 3).

Table 3: Correlation table of demographic data

*NS - Non significant

\begin{tabular}{|l|c|c|c|}
\hline JHM Correlation & P value & t value & Results \\
\hline Age & 0.3142 & 1.0068 & NS \\
\hline Height & 0.3508 & -0.9333 & NS \\
\hline Weight & 0.5269 & -0.6329 & NS \\
\hline BMI Percentile & 0.6010 & -0.5231 & NS \\
\hline
\end{tabular}

Correlation of Joint Hypermobility with Physical Activity: $r$ value $=-0.16$ and $P$ value $=0.0001$ showed that there was negative poor correlation between joint hypermobility and physical activity in the age group of 6-12 years (Table 4.1) Children with SJH showed higher physical activity level as compared to children with GJH (Table 4.2, and 4.3). Both genders with hypermobility showed moderate to high PA level. Boys showed higher physical activity level as compared to girls (Table 4.4). Avg. PA level Boys > Avg. PA level Girls.

Table 4.1: Correlation table (JHM with PAQ-C)

\begin{tabular}{|c|c|c|}
\hline Variable & r value & p value \\
\hline JHM with PAQ-C & -0.16 & 0.0001 \\
\hline
\end{tabular}

Table 4.2: Hypermobility with PAQ-C

\begin{tabular}{|l|c|c|c|}
\hline Hypermobility & Numbers & Avg. PAQ-C & PA level \\
\hline GJH & 528 & 3.28 & Mod- high \\
\hline SJH & 972 & 3.50 & Mod- high \\
\hline Total & 1500 & 3.39 & Mod- high \\
\hline
\end{tabular}

Table 4.3: Comparison of GJH with PAQ-C Boys and Girls

\begin{tabular}{|l|c|c|c|}
\hline \multicolumn{1}{|c|}{ GJH } & Numbers & Avg. PAQ-C & PA level \\
\hline Boys & 257 & 3.38 & Mod-high \\
\hline Girls & 271 & 3.19 & Mod-high \\
\hline Total & 528 & 3.29 & Mod-high \\
\hline
\end{tabular}

Table 4.4: Comparison of SJH with PAQ-C Boys and Girls

\begin{tabular}{|l|c|c|c|}
\hline \multicolumn{1}{|c|}{ SJH } & Numbers & Avg. PAQ-C & PA level \\
\hline Boys & 522 & 3.57 & Mod-high \\
\hline Girls & 450 & 3.43 & Mod-high \\
\hline Total & 972 & 3.5 & Mod-high \\
\hline
\end{tabular}




\section{Discussion}

The demographic data of present study lie within the normal height, weight and BMI percentile for both genders. ${ }^{26}$ In present study, it was found that both genders with hypermobility showed moderate to high physical activity (PA)level which is supported by the previous studies done by Ruperto $\mathrm{N}$ et al $(2004)^{21}$ $(\mathrm{n}=311,6.3-19.3$ years $)$, Pacey V et al $(2014)^{7}(\mathrm{n}=20$, 8-16 years) and Pacey $V$ et al $(2013)(n=26,7-16$ years $)^{22}$ found that there was no significant correlation between joint hypermobility and physical activity. In present study, the percentage of JHM among both gender is nearly same (1.92\%), hence the level of physical activity among both boys and girls lies within moderate to high level. The present study showed that boys with JHM have higher PA level as compared to girls (0.17) which supports the findings of previous studies. $^{8-13}$ The reason for such findings may be because physiologically boys are stronger than girls. ${ }^{28}$ Girls are physiologically hypermobile as compared to boys. ${ }^{27-28}$ In present study, GJH was more common among girls (2.66\%) as compared to boys whereas boys showed $\mathrm{SJH}$ greater than girls $(7.40 \%)$ because girls are physiologically more hypermobile. ${ }^{27-28}$ In present study, $9.69 \%$ of children (6-12 years) showed hypermobility of joints. These were all normal school going children and were apparently asymptomatic. The previous studies done in Indian population i.e. in Mumbai $=58.7 \%$ and Lucknow $=58.8 \%$ showed higher prevalence of joint hypermobility as compared to present study whereas Chennai $=17.2 \%$ (by using Carter and Wilkinson scoring system for JHM) showed similar prevalence which supports the findings of the present study i.e. $17.49 \% .^{4-5,14,19-20}$ The findings of our study fall within the range of (3-6) worldwide prevalence 13$50 \%$. In present study, SJH (32.20\%) was found to be more common as compared to GJH (17.49\%) which the results of previous study done by Adib $\mathrm{N}$ et al (2005) which says that GJH is more common as compared to $\mathrm{SJH}$ in a population of 125 hypermobile children ${ }^{2}$. In present study, the incidence of hypermobility in both genders increases as age advances from 6-10 years but shows decrement in the age of 11 and 12 year which contradict the finding of previous studies done on knee hypermobility and a study done by Adib $\mathrm{N}$ et al which says that as the age advances hypermobility reduces whereas the study done in Chennai (1996) supports the findings of present study which showed that JHM increases from the age of 6-10 years whereas it showed decrement at the age of 11-15 years. ${ }^{4,19,28}$ Girls showed GJH more than boys and JHM \% reaches its peak at the age of 10 years for both genders. This finding might be due to certain metabolic changes in children during the period of growth spurt ${ }^{29}$ (Girls=8-13 years \& Boys=914 years). In present study, incidence of JHM followed the sequence of Thumb (35.04\%) $>5^{\text {th }} \mathrm{MCP}(24.67 \%)$ $>$ Knee $(20.19 \%)>$ Elbow $(19.94 \%)>$ Lumbar $(0.16 \%)$ whereas the study done by Hasija RP et al (2008) showed the following sequence of $5^{\text {th }} \mathrm{MCP}(77.3 \%)>$ Thumb $(75.1 \%)>$ Elbow $(38 \%)>$ Knee $(28.7 \%)>$ Lumbar (17.2\%). ${ }^{4}$ In present study, spinal mobility is not so affected whereas upper limb joints are more affected and there was no significant difference between the elbow and knee joint hypermobility. This findings may be because lower limb are weight bearing joints and are suppose to be more stable whereas upper limb joints are more mobile and less weight bearing. In recent study, the gender wise ratio of the prevalence of JHM was found to be $0.93: 1$ girls/boys, which showed that boys are more hypermobile as compared to girls in the present population. The girls/boys ratio for GJH was 1.05:1 which showed that girls have GJH more common as compared to boys these findings are supported by various studies done on gender wise ratio for joint hypermobility only which showed that gender ratios ranges from proximately $3: 1$ to $2: 1$ girls/boys and girls are more hypermobile as compared to boys. ${ }^{15-20,24-}$ ${ }^{25}$ But for SJH the ratio was found to be $0.86: 1$ which showed that boys have $\mathrm{SJH}$ more common as compared to girls whereas for SJH the findings are contradicted by previous studies.

\section{Conclusion}

The present study showed that joint hypermobility affects the physical activity in children of age 6-12 years. Children with selective joint hypermobility showed higher physical activity as compared to Children with generalized joint hypermobility. The children with JHM show moderate to high level of physical activity. Joint Hypermobility (49.69\%) affects the physical activity in children of age 6-12 years. Hypermobile children Shows moderate to high level of PA. Children with SJH showed higher PA than GJH children.

\section{Clinical Implication}

Children with joint hypermobility should be regularly followed for any musculoskeletal complications.

\section{Recommendations}

Hypermobile children should be under regular supervision of pediatric rheumatologist and pediatric physical therapist. Parents of children's with hypermobility should promote for physical activity training under guidance. Schools should include screening for joint hypermobility on regular basis. Children With generalized joint hypermobility should be treated for stability and children with joint hypermobility should be advised for joint protection techniques.

\section{Implication for Future Research}

Children with upper limb and lower limb hypermobility should be examined for muscle strength, balance and upper and lower limb function in the age of 
6-12 years. There is need to evaluate whether joint hypermobility affects the fine motor Activities in children of age 6-12 years (e. g. Writing skills, etc). There is need for establishing PAQ-C for Indian children as most of the activities in PAQ-C are performed in western countries children but not in Indian scenario. Fractures and dislocations are common in children: whether JHM is the reason behind it? With this much of hypermobility prevalence (49.69\%), children should be screened for joint hypermobility in their regular health check-ups. Parents and school authority should be aware of joint hypermobility.

\section{Limitation of the Study}

The physical activity was not evaluated in nonhypermobile children.

\section{References}

1. Engelsman BS, Klerks M, Kirby A. Beighton Score: A valid measure for generalized hyper mobility in children. J Pediatr. 2011;15:8(1):119-123.

2. Adib N, Davies K, Grahame R, Woo P, Murray KJ. Joint hypermobility syndrome in childhood. A not so benign multisystem disorder? Rheumatol. 2005;44:744-750.

3. ChengJ, Chan P. Joint laxity in children. J Pediatr Orthop. 1991;11(6):752-6.

4. Hasija RP, Khubchandani RP, Shenoi S. Joint hypermobility in Indian children. Clinical and experimental Rheumatol. 2008;26:146-150.

5. Viswanathan V, Khubchandani RP. Joint hypermobility and growing pain in school children. Clinical and experimental Rheumatol. 2008;26:962-966.

6. Qureshi AU, Maalik A, Ahmad TM. Relationship of joint hypermobility and musculoskeletal problems and frequency of benign joint hypermobility syndrome in children. J Ayub Med Coll Abbottabad. 2010;22(4):150-4.

7. Pacey V, Tofts L, Adams RD, Munns CF, Nicholson LL. Proprioceptive acuity into knee hypermobile range in children with joint hypermobility syndrome. Pedia Rheumatol. 2014;12:40.

8. Janz KF, Lutuchy EM, Wenthe P, Levy SM. Measuring activity in children and adolescents using self-report: PAQ-C and PAQ-A. Med Sci Sports Exerc. 2008;40(4):767-72.

9. Maurice PFS, Welk GJ, Beyler NK, Bartee RT, Heelan KA. Calibration of self-report tools for physical activity research: the Physical Activity Questionnaire. BMC Public Health. 2014;14:461:1471-2458.

10. Kathelene Janz. Subjective and objective measures of physical activity in relationship to bone mineral content during late childhood: the Iowa Bonedevelopment study. Br J Sports Med. 2008;42(8):658-663.

11. Cliona NM, Ralph M, Yannan J, Andrew J, Harry P, Anthony R. Couch potatoes to jumping beans: A pilot study of the effect of active videogames on physical activity in children. Int J Behav Nutr and Phys Act. 2008;5:8.

12. Dan SP, Mohd NM, Zalilah MS. Determination of factors associated with physical activity levels among adolescents attending school in Kuantan, Malaysia. Malaysia J Nutr. 2011;17(2):175-87.

13. Thompson A, Baxter-Jones AD, Mirwald RL, Bailey DA. Comparison of physical activity in male and female children: does maturation matter? Med Sci Sports Exerc. 2003;35(10):1684-90.
14. Deshmukh AA. Normal values of functional reach and lateral reach tests in children with knee Hypermobility. Pediatr Phys Ther. 2014;26(2):230-236.

15. Seow CC, Chow PK, Khong KS. A study of joint hypermobility in a normal population. Ann Acad Med Sing 1999; 28:231-6.

16. EL Garf AK, Mahmoud GA, Mahgoub EH. Hypermobility among Egyptian children: Prevalence and features. J Rheumatol. 1998;25:1003-5.

17. Qvindesland A, Jonsson H. Articular hypermobility in Icelandic 12 year olds. Rheumatology. 1999;38:1014-6.

18. Rikken-Bultman DG, Wellink L, van Dongen PW. Hypermobility in two Dutch school populations. Eur J Obstet Gynecol Reprod Biol. 1997;73:189-92.

19. Subramanyam V, Janaki KV. Joint hypermobility in South Indian children. Indian Pediatr. 1996;33:771-2.

20. Abujam B. Hypermobility is related with musculoskeletal pain in Indian School children. Clin Exp Rheumatol. 2014;32(4):610-3.

21. Ruperto N, Malattia C, Bartoli M, Trail L, Pistorio A, Martini A, et al. Functional ability and physical and psychosocial well-being of hypermobile school children. Pediatr Rheumatol. 2004;22:495-498.

22. Pacey V, Tofts L, Adams RD, Munns CF, Nicholson LL. Exercise in children with joint hypermobility syndrome and knee pain: A randomized controlled trial comparing exercise into hypermobile versus neutral knee extension. Pediatr Rheumatol. 2013;11:1:30.

23. Jelsma LD, Geuze RH, Klerks MH, Niemeijer AS, Engelsman BCMS. The relationship between joint mobility and motor performance in children with and without the diagnosis of developmental co-ordination disorder. BMC Pediatr. 2013;13:35.

24. Seckin U, Tur BS, Yilmaz O, Yagci I, Bodur H, Arasil T. The prevalence of joint hypermobility among high school students. Rheumatol Int. 2005;25(4):260-3.

25. Beighton P, Solomon L, Soskolne CL. Articular mobility in an African population. Ann Rheum Dis. 1973;32:413-8.

26. Paul VK, Bagga A, editors. Ghai Essential Pediatrics. $8^{\text {th }}$ Edition. New Delhi: CBS Publishers and Distributors pvt. Ltd: Disorders. P. 28-30,32-33.

27. Lawrence A. Benign joint hypermobility syndrome, review article. J Indian Rheumatol Assoc. 2005;13:150155.

28. Deshmukh AA, Ganesan S, Tedla JS. Normal values of Functional reach and lateral reach tests in Indian school children. Pediatr Phys Ther. 2011Spring;23(1):1.

29. Oliver J. Arthritis Research UK blog (internet). Cambridge UK: Reports on the rheumatic diseases series 5, Hands On; Arthritis Research UK. 